\title{
3
}

\section{Mechanisms for Surges in Vertical Shafts in Stormwater Tunnels}

\author{
James W. Lewis, Steven J. Wright and Jose G. Vasconcelos
}

Transient analyses of filling stormwater or combined sewer systems are often conducted to determine the potential for water returning to grade through vertical manhole or ventilation shafts. Although several studies have investigated interactions with air trapped during the filling process ( $\mathrm{Li}$ and McCorquodale, 1999; Vasconcelos and Wright, 2005, 2006 and 2009; Wright et al, 2008; Zhou et al, 2002a and 2002b;), numerical models to simulate filling transients almost exclusively consider only the water phase (Capart et al, 1997; Cardle and Song, 1988; Politano et al, 2007; Vasconcelos et al, 2006). With these models, the mechanism for the return of water to grade is an inertial surge associated with the filling process, as discussed by Guo and Song (1990). The existence of air interactions allows for the possibility of other mechanisms for large water rises in vertical shafts. Previous research by the authors has indicated the ability of trapped air pockets entering vertical shafts to eject water ahead of the rising air (Lewis et al, 2010; Wright et al, 2007). This chapter presents the results of field measurements during geyser events in a stormwater tunnel system that indicate that the hydraulic grade line remained over $20 \mathrm{~m}$ below grade during events in which water was ejected $15 \mathrm{~m}$ to $20 \mathrm{~m}$ into the air.

This chapter also presents the results of laboratory experiments that were performed in a setup that involved the release of air pockets but was intended to minimize the development of inertial surges. These experiments were intended to investigate the effectiveness in mitigating surges of a configuration involving an expansion in the riser diameter. Observations of the water level in the riser attached to a horizontal pipeline with initial stagnant water and air injection were analyzed to determine the maximum water level in the

Lewis, J., S.J. Wright and J. Vasconcelos. 2011. "Mechanisms for Surges in Vertical Shafts in Stormwater Tunnels." Journal of Water Management Modeling R241-03. doi: 10.14796/JWMM.R241-03.

(C) CHI 2011 www.chijournal.org ISSN: 2292-6062 (Formerly in Cognitive Modeling of Urban Water Systems. ISBN: 978-0-9808853-4-7) 
riser. The observations indicated a fluctuating water level within the riser, with additional rise that was characterized as splash as the air burst through the water surface. Subsequent investigation indicated that the fluctuating water levels were created by inertial oscillations set up by pressure drops within the riser as the air was expelled.

Considering these laboratory observations, a relevant question is whether these inertial oscillations would also be relevant in prototype applications. This question was addressed using the numerical model by Vasconcelos et al. (2006) in an idealized scenario that was intended to reproduce initial conditions similar to those associated with the release of a large mass of air through a vertical shaft. The simulation results suggest that the occurrence of inertial oscillations driven by air release is relevant to full scale systems.

\subsection{Field Observations}

\subsubsection{System Description}

The St. Anthony Falls Laboratory at the University of Minnesota performed an investigation for the Minnesota Department of Transportation at two manholes that were prone to geyser formation in a stormwater tunnel that flowed beneath the median of Interstate $35 \mathrm{~W}$ in Minneapolis, Minnesota. A video recorder was installed near a manhole at the 35th Street overpass and recorded a large number of geyser events over $10 \mathrm{y}$. Some of these videos have made their way into the popular culture due to the dramatic nature of the events; numerous YouTube videos depict the geysers (e.g. http://www.youtube.com/watch?v=ttQqvsU08n0). What is not generally known is that pressure and velocity transducers were installed in the tunnel at the location of the manhole in question.

Data was collected from 1996 through 2005 with thirteen events recorded between 1999 and 2005. Individual events have involved more than one discrete geyser. Data is presented below for a rainfall event that occurred on the morning of July 11, 2004, and involved a sequence of nine separate geysers typically lasting $10 \mathrm{~s}$ to $25 \mathrm{~s}$ with intervals of approximately $1 \mathrm{~min}$ between the subsidence of one geyser and the onset of the subsequent one. A video record of the first two of the geysers is provided on the Minneapolis Star Tribune website (www.startribune.com/video/15509842.html). The writers have other video records from this same location that depict even stronger geysers and with different time intervals between geyser formation.

The general details of the system are:

- $\quad$ stormwater tunnel diameter $3.66 \mathrm{~m}$;

- manhole diameter $2.44 \mathrm{~m}$ (actually egg-shaped section with this height); 
- tunnel invert located $28.6 \mathrm{~m}$ below grade;

- velocities were recorded at 5 min intervals with an American Sigma area (through measured depth) velocity meter;

- $\quad$ rainfall was recorded at 1 min intervals; and

- $\quad$ pressure transducers installed at $0.47 \mathrm{~m}$ and $2.88 \mathrm{~m}$ above the local tunnel invert. The data acquisition system for pressure was programmed to record only for water depths recorded by the Sigma meter greater than $0.47 \mathrm{~m}$. Data was collected every $5 \mathrm{~s}$ for water depths between $0.47 \mathrm{~m}$ and $2.88 \mathrm{~m}$, and every $1 \mathrm{~s}$ for depths greater than $2.88 \mathrm{~m}$.

\subsubsection{Measurement Results}

The particular data presented was collected on July 11, 2004, with the pressure transducers activated at about $05: 22$ by the increase in water depth. The record shows that the velocity was relatively constant at about $1 \mathrm{~m} / \mathrm{s}$ between 05:30 and 08:50 with no indication of fluctuations indicative of inertial oscillations in the pipeline. Since the velocity data is only available at $5 \mathrm{~min}$ intervals, it is not possible to make definitive statements regarding higher frequency variation of velocity during the geyser event. Figure 3.1 shows the pressure record for a 30 min period containing the geyser event.

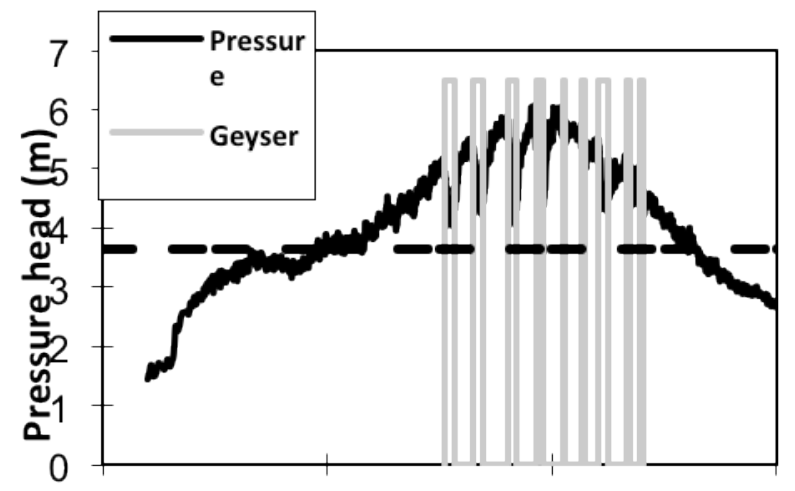

5:20:00 AM 5:30:00 AM 5:40:00 AM 5:50:00 AM

Figure 3.1 Pressure head relative to tunnel invert recorded during geyser event of July 11, 2004.

The data is from the lower pressure transducer and converted to a pressure head relative to the tunnel invert. Superimposed on the figure are the visual observations of the geyser occurrences from the video record. These are indicated by the vertical lines indicating the beginnings and ends of individual geysers; the height of the line has no relationship to pressures 
indicated on the vertical axis. The pipe crown elevation is also noted on the figure.

A number of observations can be made regarding the data presented in Figure 3.1. First of all, the pressure head never went above about $6 \mathrm{~m}$ during the entire event. Since the tunnel invert is $28.6 \mathrm{~m}$ below grade, a hydraulic explanation based on inertial surges in the tunnel is inadequate to explain the observed geysers. Another observation can be related to the observed geyser height. From the video, it is estimated that the geyser height is $20 \mathrm{~m}$. Therefore the exit velocity of the jet can be estimated by the simple conversion of velocity to elevation head as $V^{2} /(2 g)=h$, with $h$ the rise height of the water jet. Using $h=20(\mathrm{~m})$ would result in an exit velocity of $19.8 \mathrm{~m} / \mathrm{s}$, suggesting an upward discharge in the manhole of $93 \mathrm{~m}^{3} / \mathrm{s}$. This compares to a tunnel discharge of less than $9 \mathrm{~m}^{3} / \mathrm{s}$ during the geyser events according to the measured tunnel velocities, confirming that this cannot be a solid water jet. Finally, the pressure record provides no indication of inertial oscillations that would be necessary to produce the discrete geyser events as suggested by Guo and Song (1990). It therefore appears necessary to conclude that air interactions with the water flow are necessary to describe the geysers observed at this site. Wright et al. (2007) and Lewis et al. (2010) provide a hypothesis regarding the nature of these interactions based on observations in laboratory experiments.

\subsection{Laboratory Investigation}

\subsubsection{Experimental Objectives and Conditions}

The experiments were performed for the Washington DC Water and Sewer Authority (DCWASA) and were intended to address a number of issues related to air release through vertical ventilation shafts. One question was related to whether air entrained at a dropshaft could result in geyser formation if it was not removed at the dropshaft and was subsequently transported to a nearby ventilation shaft. A second issue was associated with previous suggestions by the writers that the effects of air release in a vertical shaft could be mitigated by expanding the ventilation diameter at a location above the tunnel crown (Lewis et al, 2010). These experiments were performed in a configuration that was intended to eliminate the occurrence of inertial surges associated with rapid filling. The setup was quite simple: a riser at the downstream blocked end of a horizontal pipe with a constant head reservoir at the opposite end. Air was introduced into the system as small bubbles at a constant rate through an injection point at the bottom of the pipe approximately midway along its length as indicated in Figure 3.2. 


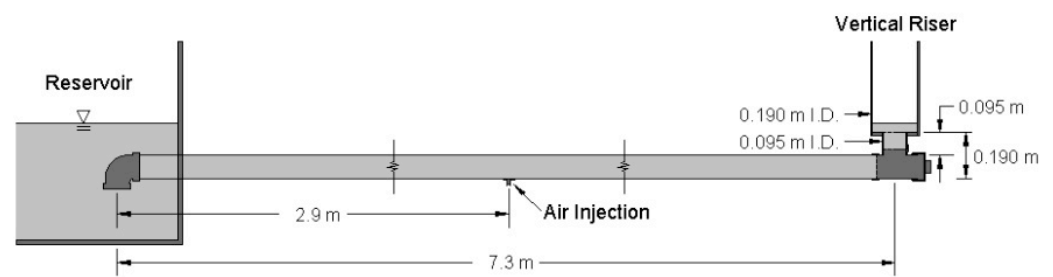

Figure 3.2 Schematic of experimental setup.

The setup provided for all air release at the riser. Although the air injection was in the form of small bubbles, these rose to the top of the pipeline and coalesced into larger air pockets as they were transported to the riser. Although there was a continuous injection of air, the air along the crown tended to form a series of discrete air pockets with completely full flow in the pipe between them. The water level in the reservoir could be adjusted to control the initial water level in the riser. The air arriving at the riser began to rise due to its buoyancy, and forced the water upwards with some downflow around the sides of the air pocket. As the air rose through the water to the surface, water was ejected upwards above the surface; this is referred to as splash in the results presented below. Both the rise of the main water column as well as the splash height were measured from video recordings; a 3 min video was recorded for each experiment and the maximum rises during that time period were used to define the vertical extent.

There were two basic experimental variables, the air injection rate and the initial water level. Two air injection rates and four different water levels were tested, as indicated in Table 3.1. Additional equivalent tests were performed with a constant diameter riser of the same diameter $(0.095 \mathrm{~m})$ as the lower portion indicated in Figure 3.2.

Table 3.1 Experimental conditions.

\begin{tabular}{ccc}
\hline Run ID & Air flow rate $(\mathrm{L} / \mathrm{min})$ & Initial water level $(\mathrm{m})$ \\
\hline 1A & 8 & 0.10 \\
1B & 25 & 0.10 \\
2A & 8 & 0.14 \\
2B & 25 & 0.14 \\
3A & 8 & 0.20 \\
3B & 25 & 0.20 \\
4A & 8 & 0.29 \\
4B & 25 & 0.29 \\
\hline
\end{tabular}

\subsubsection{Experimental Observations}

The air formed a nearly continuous layer along the crown of the pipe. Assuming the air flow is directly scalable between the model and prototype 
based on the diameter of the main tunnel, and assuming Froude number scaling for dynamic similarity, the air flow rates of $8 \mathrm{~L} / \mathrm{min}$ and $25 \mathrm{~L} / \mathrm{min}$ would correspond to $6.2 \mathrm{~m}^{3} / \mathrm{s}$ and $19.4 \mathrm{~m}^{3} / \mathrm{s}$ respectively in the Washington DC storage tunnel system $(7.0 \mathrm{~m}$ diameter tunnel). The low air flow rate occupied approximately the top $15 \%$ of the depth of flow, or $9 \%$ of the cross sectional area, while the high air flow rate occupied roughly $33 \%$ of the flow depth, or $29 \%$ of the main tunnel area. These air flow rates are significantly larger than the expected concentrations due to air entrainment at a dropshaft. The draft document for the Iowa Institute for Hydraulic Research study for the proposed drop shafts in the DCWASA system (IIHR, 2009) shows the largest rate of air entrainment of $0.21 \mathrm{~m}^{3} / \mathrm{s}$ during $48.2 \mathrm{~m}^{3} / \mathrm{s}$ water flow. This air concentration of $1.4 \%$ is roughly an order of magnitude below the $9 \%$ air concentration (based on the percentage of pipe area occupied by air). A maximum threshold for air flow within a tunnel system can be found using the Benjamin (1968) analysis for air intrusions. The air may occupy a maximum depth of one half of the tunnel diameter with an intrusion velocity of $0.54 \sqrt{ }(g D)$, corresponding to an air flow rate of $112 \mathrm{~L} / \mathrm{min}$ in the physical model, or $86.7 \mathrm{~m}^{3} / \mathrm{s}$ prototype. The air pockets were relatively large as they reached the vertical riser. From previous investigations, large air pockets are associated with the most severe geyser events.

The diameter expansion influenced the vertical release of the air pockets through the riser. Figure 3.3 shows a large air pocket expanding in all directions as it enters the larger diameter of the riser expansion.

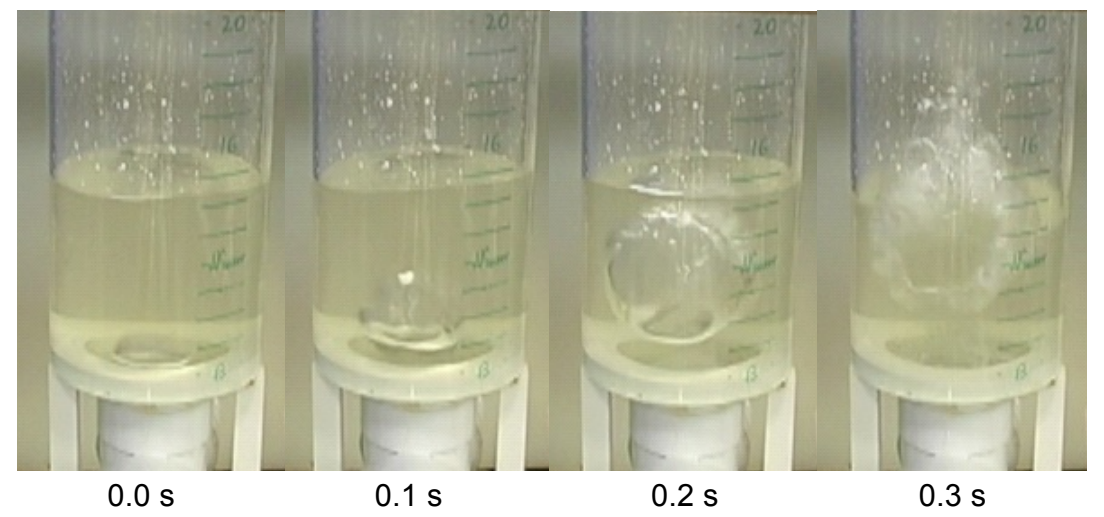

Figure 3.3 Images of air pocket expansion within vertical riser.

This volumetric expansion in the radial direction limits the continued increase of upward momentum of the rising air, thus decreasing the strength of the geyser event. This transition also serves to allow water to flow around 
the rising air pocket more easily than for a constant diameter riser. Once the top of the air pocket breaks through the free surface of the water, the behaviour becomes chaotic as subsequent air arrives and is ventilated quickly through the disrupted water in the riser. This chaotic behaviour prevents slugs of liquid from being lifted within the riser but may increase the amount of water droplets that are entrained in the upward flowing air.

\subsubsection{Experimental Results}

There are various ways to identify the strength of geyser events in these experiments. The first method, labeled splash, is to observe the maximum height of any water droplets lifted due to the escaping air. The second method, labeled surge, is to observe the maximum water surface level. In small diameter risers, the splash effect is less noticeable because the rising air tends to form a distinct interface with the water flowing downward around it. However, for large diameter risers the air does not necessarily fill the cross section and the large air pockets propel water droplets significant distances into the air as they break through the free surface. The splash height was observed for each of the eight trials using a $0.095 \mathrm{~m}$ constant diameter riser and is listed in Table 3.2 along with the surge levels. The height of the geyser measurements are relative to the tunnel invert and are presented in nondimensional form normalized by the riser diameter prior to the expansion.

Table 3.2 Geyser measurements for constant diameter riser.

\begin{tabular}{cccccc}
\hline Run ID & $\begin{array}{c}\text { Surge height } \\
(\mathrm{m})\end{array}$ & $\begin{array}{c}\text { Splash } \\
\text { height }(\mathrm{m})\end{array}$ & $\begin{array}{c}\text { Equilibrium } \\
\text { water level } \\
(\mathrm{m})\end{array}$ & $\begin{array}{c}\text { Surge above } \\
\text { E.W.L. }(\mathrm{m})\end{array}$ & $\begin{array}{c}\text { Splash above } \\
\text { E.W.L. }(\mathrm{m})\end{array}$ \\
\hline 1A & 1.86 & 2.28 & 1.09 & 0.77 & 1.19 \\
1B & 2.41 & 3.08 & 1.09 & 1.32 & 1.99 \\
2A & 2.34 & 3.88 & 1.50 & 0.84 & 2.38 \\
2B & 2.95 & 4.81 & 1.50 & 1.45 & 3.31 \\
3A & 3.21 & 5.36 & 2.09 & 1.12 & 3.27 \\
3B & 4.14 & 5.61 & 2.09 & 2.05 & 3.52 \\
4A & 4.07 & 6.96 & 3.00 & 1.07 & 3.96 \\
4B & 4.88 & 7.22 & 3.00 & 1.87 & 4.21 \\
\hline
\end{tabular}

Geyser strength can be assessed in a number of different ways. Either the splash height or the surge height from the observations could be used as a definition. Furthermore, the measurement could be based on an absolute water rise or could be expressed relative to the initial water level in the experiment, both of which are provided in Table 3.2. For geysers, we believe that the splash height is more relevant based on understood mechanisms for geyser formation as discussed above. Observations from the video records 
suggest that the water level in the riser tended to oscillate over time during the experiment and that the maximum splash height was associated with a condition in which the air pocket broke through the surface at a time in which the water surface was high due to the surge effect. From Table 3.2, it appears that the surge height is a function of air flow rate and also increases somewhat with the initial water height in the riser. Although splash height also increased with both variables, the initial water level had a more significant effect, presumably due to the greater opportunity for air pocket acceleration in the vertical riser as it rose through the longer water column.

The geyser strengths for the case of a diameter expansion from $0.095 \mathrm{~m}$ to $0.19 \mathrm{~m}$ in the vertical shaft are shown in Table 3.3, while Table 3.4 presents the reduction in geyser strength due to the diameter expansion (i.e. a comparison between the results in Tables 3.2 and 3.3).

Table 3.3 Geyser measurements for diameter expansion.

\begin{tabular}{cccccc}
\hline Run ID & $\begin{array}{c}\text { Surge height } \\
(\mathrm{m})\end{array}$ & $\begin{array}{c}\text { Splash } \\
\text { height }(\mathrm{m})\end{array}$ & $\begin{array}{c}\text { Equilibrium } \\
\text { water level }(\mathrm{m})\end{array}$ & $\begin{array}{c}\text { Surge above } \\
\text { E.W.L. }(\mathrm{m})\end{array}$ & $\begin{array}{c}\text { Splash above } \\
\text { E.W.L. }(\mathrm{m})\end{array}$ \\
\hline 1A & 1.86 & 2.21 & 1.09 & 0.77 & 1.13 \\
1B & 2.02 & 2.95 & 1.09 & 0.93 & 1.86 \\
2A & 2.47 & 3.47 & 1.50 & 0.97 & 1.96 \\
2B & 2.82 & 4.27 & 1.50 & 1.32 & 2.76 \\
3A & 3.02 & 4.43 & 2.09 & 0.93 & 2.34 \\
3B & 3.21 & 5.23 & 2.09 & 1.12 & 3.14 \\
4A & 3.63 & 5.49 & 3.00 & 0.62 & 2.48 \\
4B & 3.95 & 6.42 & 3.00 & 0.94 & 3.41 \\
\hline
\end{tabular}

Table 3.4 Geyser strength reduction caused by diameter expansion.

\begin{tabular}{ccc}
\hline Run ID & $\begin{array}{c}\text { \% Reduction in surge beyond equi- } \\
\text { librium water level }\end{array}$ & $\begin{array}{c}\text { \% Reduction in splash beyond } \\
\text { equilibrium water level }\end{array}$ \\
\hline 1A & 0 & 4 \\
1B & 30 & 7 \\
2A & -15 & 18 \\
2B & 9 & 16 \\
3A & 19 & 28 \\
3B & 45 & 11 \\
4A & 42 & 37 \\
4B & 49 & 20 \\
\hline
\end{tabular}

The maximum reduction in splash geyser strength, during experiment $4 \mathrm{~A}$, is $37 \%$ and the average splash reduction is $17 \%$. The maximum reduction of surge is $49 \%$ during experiment $4 \mathrm{~B}$ and the average surge reduction is $22 \%$. One can interpret the relative influence of both surge and splash among the various experiments by comparing the results in the first few columns of Table 3.3 to the relative changes in the fourth column (equilibrium water level, EWL). For example, the static equilibrium level change between 
the 3 and 4 series of experiments is $0.087 \mathrm{~m}$ while the changes in splashing heights are similar to this change, but the surge height increases are only in the $0.06 \mathrm{~m}$ to $0.07 \mathrm{~m}$ range. Conversely, the static level change between the 1 and 2 series of experiments is only $0.035 \mathrm{~m}$, while the increase in splash height between the two is close to $0.125 \mathrm{~m}$ and in surge height is in the 0.06 $\mathrm{m}$ to $0.08 \mathrm{~m}$ range. These counteracting trends between the two series are presumed to be related to surge dynamics, as discussed in more detail below. The initial water level drop in the series 1 experiments is low since the water level is close to the tunnel crown and the resulting surge is influenced by this. However, considering the series 3 and 4 experiments, it appears that the increase of initial mass in the riser provides a limit to the surge effects.

It has been previously noted (Lewis et al, 2010) that the small scale laboratory experiments do not reproduce all phenomena that will occur at the field scale. Specifically, at large scale, the geysers such as discussed in Section 3.1 appear as an air-water mixture whereas in the smaller scale experiments reported in this section, the air and water phases appear more distinct. Thus it should be emphasized that the observations in Tables 3.2 through 3.4 are qualitative; it is presumed that the relative trends in the variables studied is consistent to what would occur in large scale systems.

\subsection{Inertial Surge: Observations and Implications}

\subsubsection{Source of Inertial Surge}

Review of the video records clearly indicated a longer period (on the order of $10 \mathrm{~s}$ ) oscillatory response of the water level in the riser although it was punctuated with releases of discrete air pockets through the riser. After an air pocket was ejected through the water surface, the water level subsequently dropped below the equilibrium water level controlled by the reservoir head. This in turn creates a pressure gradient towards the riser that generates the inertial oscillations observed. It is emphasized that these oscillations are not due to the inertia in the tunnel filling process such as could be predicted with single phase flow filling models, but is associated with the discharge of large diameter air pockets through the riser, and therefore could only be predicted with a model framework that considers release of air pockets through vertical shafts.

A simplified numerical model that considers the inertia of the liquid in the system was implemented to compare with the observed surges. Three control volumes can be drawn (as shown in Figure 3.4) around the liquid in the main tunnel and in each section of the riser. The length of the third control volume changes as the water level within the riser changes. 


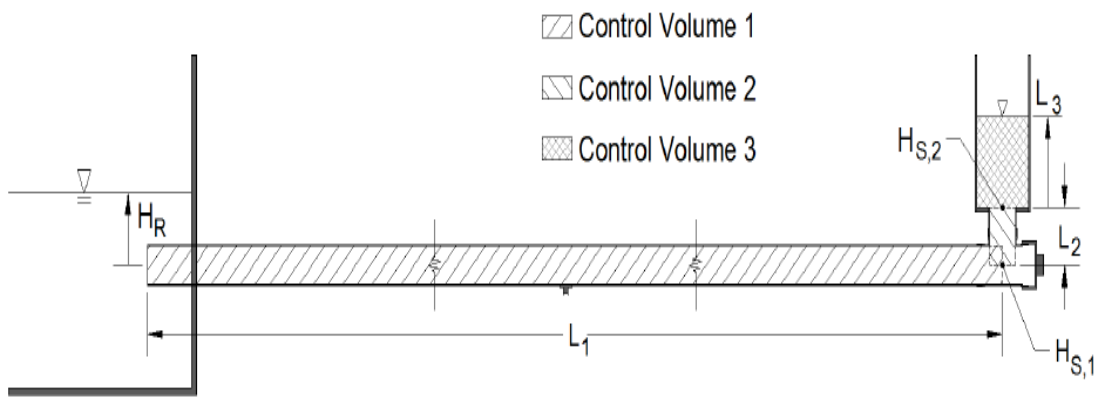

Figure 3.4 Schematic of rigid column implementation.

Conservation of mass equations can be formulated based on these control volumes to obtain Equations 3.1 through 3.3.

$$
\begin{aligned}
& \rho v_{1} A_{1}=\rho v_{2} A_{2}=\rho v_{3} A_{3} \\
& \frac{d}{d t}\left(\rho A_{3} L_{3}\right)-\rho v_{3} A_{3}=0 \quad \Rightarrow \quad \frac{d L_{3}}{d t}=v_{3}
\end{aligned}
$$

where:

$$
\begin{aligned}
\rho= & \text { constant density of water, } \\
v= & \text { fluid velocity, and } \\
A= & \text { cross-sectional area of the control volume perpen- } \\
& \text { dicular to the velocity. }
\end{aligned}
$$

With the experimental geometry, the velocities are related as:

$$
v_{1}=v_{2}=4 v_{3}
$$

Equations 3.4 through 3.6 present the momentum equations for each of the control volumes.

$$
\begin{aligned}
& \rho A_{1} L_{1} \frac{d v_{1}}{d t}=\rho A_{1} g\left(H_{R}-H_{S, 1}\right) \\
& \rho A_{2} L_{2} \frac{d v_{2}}{d t}=\rho A_{2} g\left(H_{S, 1}-H_{S, 2}-L_{2}\right) \\
& \rho A_{3} L_{3} \frac{d v_{3}}{d t}+\rho A_{3} v_{3} \frac{d L_{3}}{d t}-\rho A_{3} v_{3}^{2}=\rho A_{3} g\left(H_{S, 2}-L_{3}\right)
\end{aligned}
$$

where:

$$
\begin{aligned}
& H_{R}=\text { reservoir pressure head at the upstream end of the } \\
& \quad \text { tunnel, } \\
& H_{S, 1}=\text { pressure head at the base of the shaft, and }
\end{aligned}
$$


$H_{S, 2}=$ pressure head at the riser expansion.

Matching the pressures between the control volumes allows for the reduction of the three momentum equations to Equation 3.7.

$$
\frac{d v_{1}}{d t}=\frac{g}{L_{1}+L_{2}+\frac{L_{3}}{4}}\left(H_{R}-L_{3}-L_{2}\right)
$$

It is noted that friction and local losses (due to the riser entrance and the expansion, for example) could be included in the above formulation; these would be relatively minor in terms of their effect with the resulting effect that the surge will be slightly over-predicted with Equation 3.7 and the period of oscillation will be slightly different as well.

A specific example is used to compare the numerical model with experimental measurements. The best observation of surge oscillation was during Experiment 4A because the water level stayed within the viewable range for the longest time without air interruptions. Twice during this experiment the water level dropped to a value of $0.22 \mathrm{~m}$ above the tunnel invert while the reservoir level was $0.286 \mathrm{~m}$. Using initial conditions for this water level $\left(L_{3}\right.$ $=0.027$ ) and $v_{l, 2,3}=0$, the rigid column approach was implemented and the results are shown in Figure 3.5.

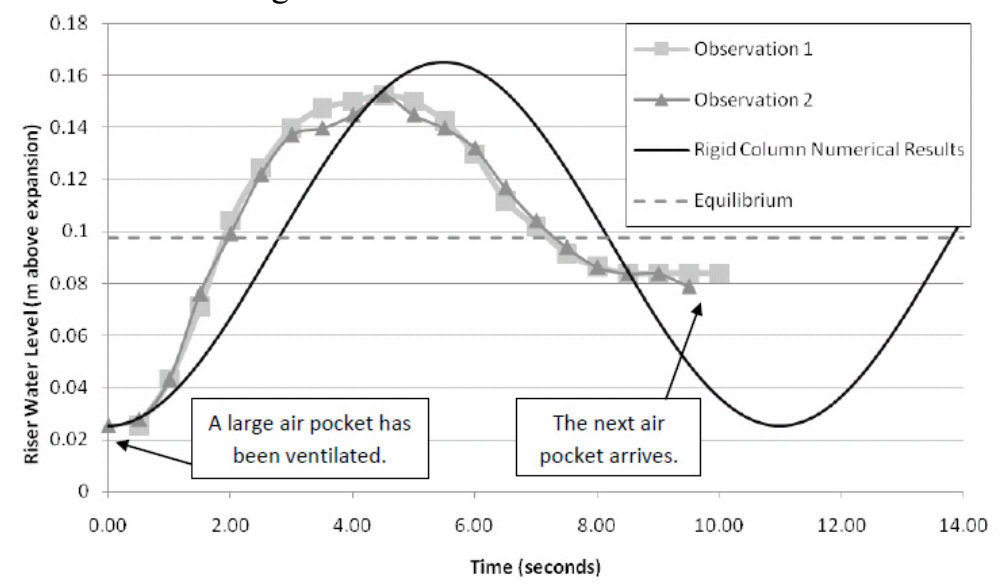

Figure 3.5 Comparison of predicted and observed riser water level elevations.

The observed water levels and associated times from the video are also shown in Figure 3.5.

Although the numerical model does fairly well to predict the behaviour of the surge oscillations within the riser, there are some discrepancies within the numerical framework. First, energy losses are neglected which would 
explain the slightly higher predicted peak surge level. Second, the fundamental period of the surge is slightly over-predicted by the rigid column approach. There are several possible explanations for this discrepancy. One is that the numerical model assumes that the pipe is completely full of water. In reality there is a significant amount of air at the crown of the pipe and this reduction in liquid mass would decrease the fundamental period of the oscillations. Another possible explanation is that the numerical model assumes that the velocities everywhere in the system are initially at rest. The continuous movement of the air pockets toward the riser somewhat reduces the validity of this assumption and could explain how the liquid in the system is able to arrive at the vertical shaft sooner than the numerical model predicts. In general, though, there is sufficient evidence to conclude that inertial surge due to air escape is the physical process responsible for the water level variations in the riser.

\subsubsection{Implications in Large Scale Systems}

The experimental testing suggests a potentially relevant issue that needs to be considered in the design of stormwater or combined sewer tunnel systems: the possibility of inertial oscillations initiated by the release of large air pockets through vertical shafts. In particular, the potential for feedback between these oscillations and the release of discrete air pockets could provide for the potential of the strong enhancement of geyser effects in some systems. An important question is whether the experimental observations reported above are only relevant at the laboratory scale or whether there are important implications in prototype systems.

In order to address this issue, simulations were performed with a hypothetical system using the two-component pressure approach developed by Vasconcelos et al. (2006). The system was a long length of straight pipe in which an initially steady flow was established by introducing a specified discharge (three different values that were chosen to be representative of the range of typical dimensionless discharges in such systems) through an upstream dropshaft, and permitting it to overflow at a downstream shaft. A vertical riser with the same diameter as the tunnel was simulated at the middle of a $10 \mathrm{~km}$ long, $8 \mathrm{~m}$ diameter tunnel. This riser was then provided with an internal boundary condition that instantaneously dropped the hydraulic grade line to the crown of the tunnel at a time of $6000 \mathrm{~s}$ as if the release of a large diameter air pocket had suddenly evacuated the riser. The simulated response to this transient event is depicted in Figure 3.6 with a presentation of the time history of the water level in the riser. 
The initial level of $8 \mathrm{~m}$ corresponds to the water level dropped to the tunnel crown with the subsequent transient response as the tunnel returns to a steady state condition. At the largest discharge, the surge induced by the reflection of the transient from the ends of the system is approximately $10 \mathrm{~m}$ with lower surge heights for smaller dimensionless discharges.

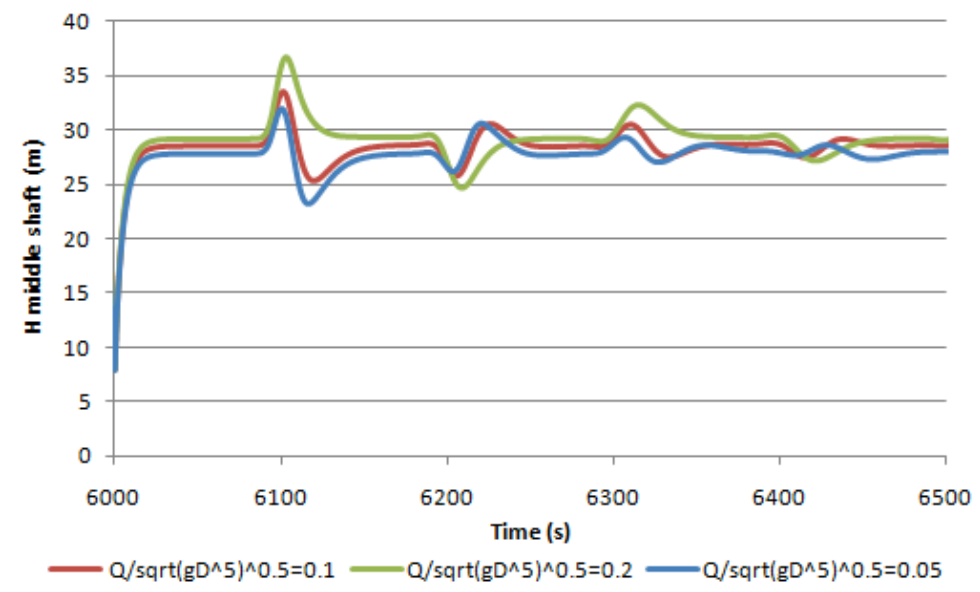

Figure 3.6 Numerical simulation of transients generated by instantaneous evacuation of water in riser at middle of a $10 \mathrm{~km}$ tunnel for three different initial discharges.

\subsection{Conclusions}

A series of experiments with constant air injection into a horizontal pipeline that was otherwise at rest was performed in order to investigate the influence of the air release on water level rise in a vertical riser connected to the pipe. A number of observations and conclusions are derived from this study:

1. As a large air pocket breaks through the free surface within the riser a chaotic, or churning, behaviour develops as the air continues to escape. Splashing of water droplets rose significantly higher than the free surface level of the liquid;

2. The geyser strength, including what is labeled splash for this study, increases as the equilibrium water level increases. The buoyant air pocket accelerates longer within higher water columns, creating more upward momentum as it reaches the free surface;

3. The diameter expansion within the riser effectively reduced the increase of upward momentum of the air pocket by caus- 
ing a radial expansion. The shaft expansion also allows for a significant amount of water to flow downward around the rising air pockets. When compared to a constant diameter riser, the splash height is reduced by an average of $17 \%$ and the surge height is reduced by an average of $32 \%$;

4. Once a large air pocket is released, a low local pressure may develop that initiates a flow toward the riser. The inertia of this liquid causes an overshoot of the equilibrium pressure in the system. A rigid column model prediction was compared to the experimental observations for a specific test. Small discrepancies can be explained by the assumptions of the numerical model. The relative success of the numerical model to explain observations reveals that inertial surge driven by air escape is taking place within the vertical shaft;

5. These results suggest an important challenge in numerical modeling in that the dynamics of air release at vertical shafts needs to be coupled with the water flow in the nearly horizontal tunnel to simulate this observed behaviour; and

6. Simulations applied to a hypothetical full scale system suggest that inertial surges induced by escape of large air pockets through vertical risers can be important and the effect should be considered in the design of tunnel systems.

\section{References}

Benjamin, T. B. (1968). Gravity currents and related phenomena. J. Fluid Mech., 31(2), 209-248.

Capart, H., Sillen, X. and Zech, Y. (1997). Numerical and experimental water transients in sewer pipes. J. Hydr. Res. 35(5), 659-670.

Cardle, J.A. and Song, C.S.S. (1988). Mathematical modeling of unsteady flow in storm sewers. Int. J. Eng. Fluid Mechanics, 1(4), 495-518.

Guo, Q. and Song, C. C. S. (1991). Dropshaft hydrodynamics under transient conditions. J. of Hydr. Engrg., 117(8), 1042-1055.

IIHR (2009). Iowa Institute of Hydraulic Research draft document. University of Iowa.

Lewis, J., S.J. Wright and J. Vasconcelos. 2010. "Physical Investigation of Discrete Air Pocket Migration and Release in CSO Storage Tunnels." Journal of Water Management Modeling R236-06. doi: 10.14796/JWMM.R236-06.

Li, J. and McCorquodale, A. (1999). Modeling mixed flow in storm sewers. J. Hydr. Engrg., 125(11), 1170-1180.

Politano, M., Odgaard, A.J. and Klecan, W. (2007). Case study: Numerical evaluation of hydraulic transients in a combined sewer overflow tunnel system. J. Hydr. Engrg., 133(10) 1103-1110. 
Vasconcelos, J. and S.J. Wright. 2005. "Applications and Limitations of Single-Phase Models to the Description of the Rapid Filling Pipe Problem." Journal of Water Management Modeling R223-19. doi: 10.14796/JWMM.R223-19.

Vasconcelos J.G. and Wright, S.J. (2006). Mechanisms for air pocket entrapment in stormwater storage tunnels. Proceedings of World Water and Environmental Resources Congress, Omaha, Nebraska, Paper 40856-14275.

Vasconcelos, J.G., Wright, S.J. and Roe, P.L. (2006). Improved simulation of flow regimetransition in sewers: two-component pressure approach. J. Hydr. Engrg., 132(6), 553-562.

Vasconcelos, J.G. and Wright, S J. (2009). Investigation of rapid filling of poorly vented stormwater storage tunnels. J. Hydr. Res. 47(5), 547-558.

Wright, S J., Creech, C.T., Lewis, J.W. and Vasconcelos, J.G. (2008). Mechanisms of flow regime transition in rapidly filling stormwater storage tunnels. Environmental Fluid Mechanics, $\underline{8}, 605-616$.

Wright, S.J., J. Lewis and J. Vasconcelos. 2007. "Mechanisms for Stormwater Surges in Vertical Shafts." Journal of Water Management Modeling R227-05. doi: 10.14796/JWMM.R227-05.

Zhou, F., Hicks, F. E. and Steffler, P. M. (2002a). Observations of air-water interaction in a rapidly filling horizontal pipe. J. Hydr. Engrg., 128(6), 635-639.

Zhou, F., Hicks, F. E. and Steffler, P. M. (2002b). Transient flow in a rapidly filling horizontal pipe containing trapped air. J. Hydr. Engrg., 128(6), 625-634. 
